\title{
BIBLON: plataforma de incentivo a leitura literária para crianças
}

\author{
BIBLON: platform to incentive literary reading to children
}

\begin{abstract}
Cassia Cordeiro Furtado
Doutoranda em Informação e Comunicação em Plataformas Digitais da Universidade de Aveiro, Portugal. Professora do curso de Biblioteconomia da Universidade Federal do Maranhão

E-mail: cfurtado@ua.pt
\end{abstract}

Lidia Oliveira

Doutora em Ciências e Tecnologia da Comunicação na Universidade de Aveiro, Portugal. Professora no Departamento de Comunicação e Artes da Universidade de Aveiro, Portugal.

E-mail: lidia@ua.pt

\begin{abstract}
Resumo
Com o avanço vertiginoso das TIC, e ultimamente com a web 2.0, presencia-se um novo fenômeno com relação à leitura e a literatura, têm-se uma nova geração de leitores-escritores, com características e necessidades contemporâneas e as instituições educacionais, em especial a biblioteca, devem repensar suas estratégias na formação de leitores na Sociedade da Informação. O presente artigo descreve pesquisa sobre a biblioteca escolar e o uso dos social media (redes sociais), no incentivo à prática da leitura-escrita, tendo como objetivo principal propor um modelo de construção de rede social de leitores e escritores, para a comunidade escolar do $1^{\circ}$ ciclo do ensino básico. Na fase empírica está sendo trabalhada a plataforma Biblon, pela comunidade do Agrupamento das Escolas de Aveiro, Portugal. Como resultado espera-se melhorar a qualidade e motivação para leituraescrita; ampliar a presença de conteúdos na língua portuguesa no ambiente da web; potencializar o uso do computador Magalhães; contribuir para integração das TIC com as bibliotecas escolares, nas atividades com a literatura infantil e oportunizar espaço para criação e interação em torno do texto literário.
\end{abstract}

Palavras-chave: leitura, escrita, redes sociais, literatura infantil, Biblon.

\begin{abstract}
With the breathtaking advance of TIC, and ultimately with web 2.0, there is very new phenomenon in relation to reading and literature, have a new generation of readers-writers, with features and contemporary needs and educational institutions, especially the library, must rethink their strategies in training readers in the Information Society. This paper describes research on the school library and the use of social media (social networking), in encouraging the practice of reading, writing, having as main objective to propose a model for constructing social network of readers and writers for the school community 1 st cycle of basic education. In the empirical phase is being worked the platform Biblon, the community of the Agrupamento de Escolas de Aveiro, Portugal. As result it is expected to improve the quality and motivation for read-write, expand the presence of content in Portuguese in the web environment, enhance use computer Magalhães; contribute to the integration of TIC in school libraries, activities with child literature and creating an space of creation and interaction around the literary text.
\end{abstract}

Keywords: reading, writing, social networking, children's literature, Biblon. 


\section{Introdução}

Uma das características do século XXI é o contexto permanente de transformações em todas as esferas da sociedade, acarretando mudanças em práticas já consolidadas, como exemplo tem-se a leitura e a escrita. Assim, são necessárias inovações de fomento, a leitura, a escrita literária, por parte das instituições educacionais.

A biblioteca escolar, que tem como usuários os principais atores do universo digital, carece de envolvimento no paradigma da web 2.0, de maneira a oferecer novos serviços e produtos às crianças e jovens. Contudo, sem esquecer suas funções tradicionais como o incentivo a leitura, em todos os contextos e diferentes suportes.

As "novas" tecnologias proporcionam ambiente de comunicação e partilha de informação, notadamente com a formação de redes sociais. O ambiente de partilha e cooperação que abrange as redes sociais proporciona novas oportunidades para criação e manutenção de comunidades de leitores-autores.

É neste contexto que se desenvolve a investigação, que alimenta o presente texto. Esta análise está focada num caso específico da rede social de leitores juniores, a plataforma Biblon, concebida com o intuito de agregar as crianças do $1^{\circ}$ ciclo, da educação básica, do Agrupamento de Escolas de Aveiro, Portugal, em espaços de leitura literária.

\section{Leitura e Literatura}

$\mathrm{Na}$ área da Educação, em particular, ler ainda pode ser sinônimo de alfabetização, habilidade de ler e escrever textos gráficos, o que resulta, em regra, do processo da escolarização. Porém, torna-se fundamental desvincular a leitura da descodificação da escrita gráfica impressa e observar os aspectos sociais das práticas de leitura e escrita, dar ênfase às práticas dos leitores que extrapolam o processo da alfabetização.

A leitura deve ser vista como um ato social de interação entre sujeitos, o autor e o leitor, porém essa interação

\footnotetext{
não é um processo unidirecional, do escritor para o leitor. A leitura envolve mais do que a mera decodificação de símbolos. A leitura envolve significação, que envolve a compreensão. Trata-se de pensamento, ação e reação. Um bom leitor vai ler o que está declarado, mas também ler o que não é declarado, um bom leitor irá relacionar o que é lido com seu conhecimento e experiência, e assim ser levado à decisão, ou, talvez, a indecisão, quando crenças são desafiadas. Ler é resposta (ROYCE, 2004, p.255, tradução nossa).
} 
Considera-se assim, que o texto exerce mediação, estabelece relações entre os leitores, onde cada indivíduo atribui ao texto um sentido particular. A leitura, então, é um espaço de interação consigo e com os outros "cuja dinâmica envolve componentes sensoriais, emocionais, intelectuais, fisiológicos, neurológicos, bem como culturais, econômicos e políticos" (MARTINS, 1983, p.31).

Apesar da escola ainda se constituir o principal espaço de aprendizagem, valorização e consolidação da leitura e escrita, percebe-se a necessidade da leitura ser considerada, notadamente pelas crianças e jovens, como instrumento para toda a vida, de compreensão, crítica e emancipação dos dogmas da sociedade e não somente atrelada ao processo de escolarização. Aponta-se que a leitura é a base para o crescimento individual e, consequentemente, para o progresso educacional.

Dessa forma, enfatiza-se que a leitura é uma atividade intelectual, que envolve habilidades de reflexão, crítica e memória, com forte influência do contexto social, cultural, cognitivo e emocional, que proporciona ao indivíduo informação, conhecimento e, também, prazer.

Nesse sentido, alerta-se para o propósito da leitura ou, como se refere Bourdieu e Chartier (1996), as maneiras de ler; ler com a idéia de prazer e não de dever, a leitura para o divertimento e a leitura com propósito funcional, fins educativos, profissionais ou informacionais.

A leitura literária é definida como a leitura com finalidade de divertimento e prazer, realizada em textos literários, escolhidos a partir de interesses e preferências pessoais. Considera-se que a leitura de obras de literatura, entendida como uma expressão artística contribui, de maneira mais eminente, para a consolidação do pensamento crítico e criativo e aguça as emoções por efeito estético.

É de salientar que, a leitura literária é tão relevante quanto à leitura funcional. Ziraldo Pinto (2003), escritor brasileiro de literatura infantil, propaga a notória frase: "ler é mais importante que estudar". Em 2007, a International Federation of Library Associations and Institutions /Libraries for Children and Young Adults Section - IFLA declarou a esse respeito;

\begin{abstract}
Apesar de ser um tipo especial de leitura, é importante salientar que a leitura por prazer demanda da mesma base que a leitura funcional. Tanto a leitura por prazer, como a leitura funcional, dependem da habilidade de leitura, pois apenas um leitor competente, que domina todos os processos cognitivos e mecânicos da leitura é capaz de gostar de ler, e através da leitura pode-se desenvolver e aprender sobre si mesmo e sobre outras pessoas (IFLA, 2010) (tradução nossa).
\end{abstract}

A literatura infantil é conceituada, tradicionalmente, como um ramo da literatura destinada para crianças de dois a dez anos. Teve seus primórdios no final do século XVII, InCID: R. Ci. Inf. e Doc., Ribeirão Preto, v. 2, n. 1, jan./jun. p. 68-85 , 2011. 
como ação formadora, com finalidade de apresentar modelos e valores para integrar as crianças à sociedade (ABRAMOVICH, 1994). Porém, já faz algum tempo, que esse padrão para literatura infantil é contestado, exemplifica-se com a posição do escritor Carlos Drummond de Andrade (1944, p. 220):

\begin{abstract}
O gênero "literatura infantil" tem, a meu ver, existência duvidosa. Haverá música infantil? Pintura infantil? A partir de que ponto uma obra literária deixa de construir alimento para o espírito da criança ou do jovem e se dirige ao espírito adulto? Qual bom livro para crianças, que não seja lido com interesse por um homem feito? Qual o livro de viagens ou aventuras, destinado a adultos, que não possa ser dado às crianças, desde que vazado em linguagem simples e isento de matéria de escândalo?
\end{abstract}

Cecília Meireles (1984, p.20), além de escritora, exerceu a profissão de professora, e também apresentou opinião de vanguarda sobre a temática.

\begin{abstract}
Existe uma literatura infantil? Como caracterizá-la? Evidentemente, tudo é uma literatura só. A dificuldade está em delimitar o que se considera como especialmente do âmbito infantil. São as crianças, na verdade, que o delimitam, com sua preferência. [...] Seria mais acertado, talvez, assim classificar o que elas lêem com utilidade e prazer. Não havia, pois, uma Literatura Infantil a priori, mas a posterior.
\end{abstract}

De tal modo, coaduna-se a posição dos autores supracitados e considera-se literatura infantil como a literatura que sensibiliza e desperta interesse nas crianças.

Com o passar do tempo, surgiram novos padrões e o texto para as crianças contemporâneas mudou de maneira significativa, o aspecto educacional deixou de ser o primordial, cedendo espaço para o lúdico. A realidade social agora é apresentada em formato de diversão e lazer, através do imaginário, das emoções, incentivo à criação, curiosidade e reflexão crítica, fundamentais para o desenvolvimento infantil. Porém, a literatura infantil ainda continua com um papel muito importante, incentivar o hábito de leitura nas crianças. Torna-se relevante assinalar que é na infância e na adolescência a fase prefencial para estimular esse hábito.

O Manifesto da IFLA/UNESCO para Biblioteca Escolar, que data de 1999, estabelece a biblioteca escolar como responsável pelo desenvolvimento e promoção do prazer da leitura. Assim, percebe-se que a biblioteca da escola deve incentivar a leitura informacional e, principalmente, a leitura como entretenimento e prazer, proporcionando acesso à literatura e oportunizando a leitura lúdica. A biblioteca não pode limitar-se a complemento à aprendizagem formal da leitura realizada na sala de aula. É de salientar que a biblioteca escolar tem um papel diferenciado da escola com relação à leitura, à escola ensina a ler e a escrever, a biblioteca incentiva a prática e o prazer da leitura. 
A biblioteca escolar é o lugar de disseminação e socialização do texto literário. Para tanto, deve valer-se de estratégias originais e atividades lúdicas com o livro de literatura, incluindo os recursos das tecnologias de informação e comunicação.

A biblioteca escolar tem como público alvo a "geração net", ou seja, crianças e jovens que nasceram e vivem num contato habitual e intenso com a tecnologia (TAPSCOTT, 2010) e que usam essa tecnologia como instrumento para partilha de informação e conhecimento. Nesse sentido, deve desenvolver atividades unindo o texto literário impresso e digitalizado e oferecer serviços que proporcionem a troca de experiências relacionadas à leitura e aos livros de literatura, objetivando, assim, conquista de seus usuários.

\section{Novos Leitores e Novos Autores}

O impacto das tecnologias de informação e comunicação na sociedade acarreta transformações em práticas anteriormente já solidificadas. E, com a entrada da web 2.0 na rotina dos indivíduos, aspectos culturais estão passando por mutações históricas. Privilegiando as pessoas e suas relações, a web social amplia as possibilidades de leitura e escrita, com a inclusão dessas práticas também em media digitais, como wikis, blogs e redes sociais.

Assim, percebe-se que o processo leitura e escrita tem forte relação com a história e cultura, influenciando e sendo influenciada pelas transformações que afetam a sociedade civil. Chartier $(1991,1999)$ designa como historicidade do sujeito leitor, que o considera passível de transformação e adequação em virtude das mudanças sociais e tecnológicas.

Um dos temas mais polêmicos na atualidade é sobre o fim da era dos livros tradicionais e sua concorrência e/ou permuta com as multimedias interativas. A história registra que sempre que ocorre a introdução de nova tecnologia em nossa tradição surgem debates similares, a exemplo da invenção dos tipos móveis por Gutenberg, do cinema e dos videocassetes.

Zilberman (2001, p.118) analisa o contexto no documento "Fim do livro, fim dos leitores?" e prenuncia

a lógica do capitalismo, fundada na obsolescência programada, sugere que o livro não vai desaparecer, porque encontrará seu nicho no sistema. Talvez se torne ainda mais elitizado; ou, pelo contrário, ameaçado de desaparecimento, providencie no barateamento do custo e à renovação de popularidade. 
Neste embate, considera-se que o relevante é focar a estratégia no leitor, no texto literário e no autor e não priorizar a tecnologia, que se baliza a um instrumento. Considera-se que a leitura do livro em papel e digital são processos distintos, insubstituíveis e complementares, onde cada processo tem sua importância na vida dos indivíduos. O cerne da questão é o futuro da leitura e não o formato do livro ou seu suporte!

O livro impresso não submergirá, pois o seu manuseio provoca sensações únicas, desde a textura do papel, passando pelo cheiro inigualável do mesmo. Afora sua durabilidade comprovada secular, nada comparada com a do livro digital. "A conclusão é óbvia: tal qual a roda, o livro é uma invenção consolidada, a ponto de as revoluções tecnológicas, anunciadas ou temidas, não terem como detê-lo" (ECO, 2010).

Outro ponto de debate, com o advento das tecnologias, é a questão se as mesmas contribuem para o inventivo da leitura e escrita. $\mathrm{O}$ contexto digital presente caracteriza-se por ser marcado por substituições de paradigmas, aqui em evidência o aspecto social e cultural, assim, não cabe comparação da intensidade e qualidade da leitura com momentos anteriores. Haja vista que, as transformações sociais trazem implicações nas práticas da leitura e da escrita, como observa Chartier (1999, p. 13) "a revolução do livro eletrônico é uma revolução nas estruturas do suporte material do escrito assim como nas maneiras de ler".

Em época não muito remota ao falar-se em leitura vinha em mente os signos alfabéticos, livros e instituições como escola e biblioteca, hoje a leitura envolve uma multiplicidade de signos, de documentos e está desvinculada de uma instituição específica. Lê-se vídeos, sites, textos, imagens, chat... E as crianças e jovens são modelos para a sociedade do que atualmente é prática de leitura, em vários media e simultaneamente. "A tecnologia está influenciando a maneira como as crianças pensam e se comportam, mas se trata de mão dupla - a maneira como as crianças pensam e se comportam está influenciando e moldando a própria internet" (TAPSCOTT, 2010, p.69).

Os recentes dados do Programme for International Student Assessment - PISA, publicados em 2010, evidenciaram a questão e alguns educadores, de vários países, discordam dos resultados com relação à capacidade de leitura dos estudantes. A professora universitária brasileira Rosa Farah, citada por Mandelli (2010) explica o atual hábito de leitura dos jovens; “o adolescente lê e escreve muito, comunica-se muito mais por escrito. As gerações anteriores liam só os livros da escola. Os jovens de hoje não: estão sempre se informando dentro dessa vida social digitalizada".

InCID: R. Ci. Inf. e Doc., Ribeirão Preto, v. 2, n. 1, jan./jun. p. 68-85 , 2011. 
No contexto europeu, Aunión (2011) afirma que o aluno é ensinado na escola, mas educado no ciberespaço e cita o profesor Miguel Marzal, da Universidade Carlos III, de Madrid, completando que "leen menos la lectura escolar, incluida la de ficción, por pertenecer a un espacio de enseñanza, ajeno a la inmediatez y al discurso electrónico, interactivo y sobre todo muy visual, del ciberespacio, pero leen mucho y escriben mucho en redes sociales" (AUNIÓN, 2011).

A propósito, a editora Baen Books, que publica livros de ficção "constatou que as vendas de seus livros impressos aumentaram consideravelmente após serem publicados gratuitamente, em formato digital" (ALMEIDA, 2008, p.37).

Assim, considera-se que a tecnologia de informação e comunicação, de maneira especial a web 2.0, pode expandir as oportunidades de leitura e escrita, e dessa maneira ser parceira do livro tradicional no incentivo a essas práticas. Apesar de reconhecer que a leitura na tela apresenta vários problemas, aqui se destaca; é uma leitura mais fragmentada, com menos profundidade e mais genérica, descontextualizada, não hierarquizada, exige menos atenção e não potencializa o pensamento crítico (MILLÁN, 2008; CARR, 2008; VÁZQUEZ, 2010). Completa-se que "ler on-line não é em si uma atividade intelectualmente menos desafiadora do que ler um livro. É apenas diferente e requer habilidades diferentes" (TAPSCOTT, 2010, p.139, tradução nossa).

Celaya (2008) sugere que as tecnologias devem ser incorporadas nos planos de promoção a leitura e ao livro,

\footnotetext{
Hace ya mucho tiempo que estas herramientas electrónicas dejaron de ser tan sólo un pasatiempo al convertirse en los principales canales de comunicación e información de las nuevas generaciones. [...] A través de estas tecnologías podemos crear espacios de lectura y escritura más cercanos a su manera de comunicarse, lo que motivará en el futuro su placer por leer todo tipo de textos en todo tipo de soportes.
}

As tecnologias sociais, por valorizarem o contributo coletivo, oportunizam aos leitores a leitura interativa e capacidade de expressão, sendo assim instrumentos relevantes para aquisição de informações sobre o texto litérario, interação entre leitores, livros e autores e, consequentemente, conduzem ao estímulo da prática da leitura e escrita. A web 2.0 oferece ainda maior motivação para a literatura devido à convergência de múltiplas linguagens e oportunidade de espaço para criação em torno do texto literário. As atividades colaborativas em torno da literatura envolvem ações, em que a pessoa precisa expor sobre sua leitura. Tal ato acarreta resultados positivos para todos os envolvidos, tanto para quem recebe a nova InCID: R. Ci. Inf. e Doc., Ribeirão Preto, v. 2, n. 1, jan./jun. p. 68-85, 2011. 
informação, que entra em contato com novos conhecimentos, experiências e interpretações, como e ainda mais, para quem produz, pois tem a oportunidade de expressar sua experiência, prática e conhecimento.

A lucididade e o prazer proporcionado pela leitura literária se eternizam, "é uma experiência, acontece na nossa cabeça e acontece no nosso coração. A literatura não é feita de papel", argumenta Meade (2010) quando esteve no IV Encontro Internacional do PNL, realizado em Lisboa (informação verbal).

"Formar leitores de textos literários no contexto da era da imagem e da era da sofisticação tecnológica implica estar aberto à vinculação desses textos a diferentes suportes, utilizando-se linguagens de natureza variada" (RÖSING; SILVA, 1999, p.166). O argumento fica mais intenso quando se trata de incentivo a leitura literária pelas crianças, assim, uma ótima estratégia é aliar ao texto literário o fascínio que as mesmas têm pela sinergia entre os vários códigos. Vale destacar que, em se tratando da literatura infantil, considera-se a mesma de vanguarda, pois precedeu a era da convergência de linguagens ao unir palavras e imagens com o objetivo de atrair e estimular a leitura, sensibilizar o leitor, além adornar e enriquecer a estética literária.

A biblioteca escolar incumbida da responsabilidade de efetivar o gosto pela leitura trabalha agora em novo panorama, seu usuário potencial tem as tecnologias incorporadas de forma natural e imediata nas suas rotinas sociais, comunicativas, informacionais, educacionais e de lazer. Nesse sentido, percebe-se a necessidade da instituição se aproximar dos seus utilizadores. Conhecer as estratégias que usam para criar, compartilhar, colecionar e organizar a informação, a forma como se comunicam e se socializam e, também, acolher a maneira como aproveitam o ócio, torman-se fundamentais para a biblioteca manter-se presente e viva para seu público e para a sociedade em geral.

A esse respeito, a UNIVERSIA, rede universitária presente em países da Ibera América, publicou dados de investigação realizada, com estudantes universitários em 23 países, sobre o que os jovens pensam sobre as bibliotecas. Os dados assinalam que $72 \%$ dos investigados consideram a biblioteca como uma instituição de futuro, mas 99\%, da amostra, consideraram que a mesma carece de renovação (UNIVERSIA, 2010).

Para contornar a situação, pode-se utilizar a indicação de Chartier (2002, p.121) "a ambição para as bibliotecas do futuro poderia ser reconstituir ao redor do livro as sociabilidades que perdemos". Essa estratégia vai ao encontro de uma das características da InCID: R. Ci. Inf. e Doc., Ribeirão Preto, v. 2, n. 1, jan./jun. p. 68-85 , 2011. 
nova geração apontada por Tapscott $(2010$, p.110) que é a cultura do relacionamento e da colaboração.

Com base nos argumentos, sugere-se que a biblioteca escolar deve ser o principal caminho de interação entre os leitores e destes com a literatura, tanto em texto impresso como no mundo digital, e fazer a convergência entre essas pessoas e linguagens. Partilhar leituras deve ser encarado como uma maneira de incentivar a prática da mesma. A biblioteca tem vocação para ser o local da linguagem compartilhada (PETIT, 2008, p.99) e partilha e cooperação deve a essência para o incentivo à leitura literária de crianças e jovens.

Entretanto, observa-se que na web existe ainda uma carência de espaços onde as crianças possam trocar impressões, interpretações sobre textos literários, discutir a obra, permutar informação sobre autores, trocar sugestões de livros, divulgar suas recriações e, também, considera-se que esse espaço deve ser criado em torno da biblioteca escolar.

Nesse sentido, apresenta-se o Projeto Biblon, como uma plataforma a ser utilizada como espaço de cooperação, criatividade, ludicidade da comunidade escolar.

\section{Projeto BIBLON}

A presente investigação subordinada ao título Rede Social de Leitores-Escritores Juniores, com enquadramento nas áreas de Ciência da Informação, Comunicação e Educação, integra-se no Programa Doutoral em Informação e Comunicação em Plataformas Digitais, do Departamento de Comunicação e Artes, da Universidade de Aveiro e da Faculdade de Letras, da Universidade do Porto.

A pesquisa visa o estudo e compreensão do fenômeno de formação de comunidades de leitores-escritores, em torno da biblioteca escolar, com o uso dos social media - web 2.0 (O'REILLY, 2005). Como fruto da pesquisa pretende-se apresentar proposta de conceptualização de um modelo de construção de comunidade de leitores-escritores para a educação básica, baseado na filosofia de comunidade de prática (WENGER, 1998; WENGER et al., 2002), tendo como plataforma o Biblon (www.portal-biblon.com). O estudo de caso é realizado nas escolas do $1^{\circ}$ ciclo da escolaridade básica, em Aveiro - Portugal.

A plataforma Biblon foi elaborada por uma equipe interdisciplinar do Departamento de Comunicação e Arte da Universidade de Aveiro. No âmbito do Mestrado em Comunicação Multimédia, os alunos Paulo Valbom e Cátia Resende foram responsáveis pela criação e implementação da plataforma, com a contribuição de doutoranda Cássia Furtado, com relação InCID: R. Ci. Inf. e Doc., Ribeirão Preto, v. 2, n. 1, jan./jun. p. 68-85 , 2011. 
à proposta de conteúdos e serviços e dinamização do portal. Sendo a Professora Doutora Lídia Oliveira, pesquisadora do CETAC.MEDIA, responsável pela orientação da equipe.

Após a formação da equipe inicial, foram realizadas reuniões, de dezembro de 2009 a janeiro de 2010, com a Direção do Agrupamento de Escolas de Aveiro e professores bibliotecários para a apresentação da idéia inicial da plataforma Biblon, visando adesão para parceria com as escolas.

Para concepualização da plataforma Biblon foram aplicadas entrevistas com alunos com o objetivo de identificar as expectativas, idéias, percepções e atitudes acerca da plataforma. O teste de usabilidade da versão beta foi realizado pela equipe, em maio de 2010, a fim de identificar a satisfação e detectar as dificuldades encontradas pelas crianças no uso da mesma, visando à correção e ajuste necessários.

Para o uso do Biblon nas escolas foi assinado convênio entre a Universidade de Aveiro e o Agrupamento de Escolas de Aveiro, em decorrencia, a fase empírica da investigação ocorre junto às escolas EB1 da Vera Cruz, EB1 de Santiago, EB1 das Barrocas e EB1 da Gloria, do ensino básico, do $1^{\circ}$ ciclo, do $2^{\circ}$ ao $4^{\circ}$ ano.

$\mathrm{Na}$ primeira fase, foram realizadas oficinas de formação de utilizador, tendo como público os educadores das referidas escolas, com o objetivo de divulgar e explicar as funcionalidades do Biblon, discutir sobre as atividades a serem desenvolvidas (focus group) e elaborar cronograma de atividades, na biblioteca e em sala de aula, que objetivem o estímulo à leitura e trabalho com a literatura infantil com o uso da plataforma.

A fase seguinte, que está a ocorrer, são realizadas formação de utilizadores com os alunos visando disseminar e esclarecer as ferramentas do Biblon e estimular o seu uso, como instrumento para a prática da leitura literária, no contexto da escola e também no cotidiano das crianças.

Conscientes que o processo de formação de leitores passa pelo envolvimento da família, a equipe do Biblon, informa os pais dos alunos, através de correspondência entregue no ato da formação, sobre o objetivo do referido projeto, assim como também solicita a colaboração e participação no uso da plataforma, visando sensibilizá-los que a leitura partilhada e uso das tecnologias são estratégias inovadoras para o incentivo à leitura literária das crianças. 
No contexto desta investigação, tem-se como foco atender a seguinte pergunta: a biblioteca escolar, com o uso dos social media (redes sociais) pode incentivar a prática da leitura/escrita?

Uma vez que, as ferramentas sociais da web 2.0 começam a estar presentes no domínio das bibliotecas, convém refletir sobre o papel das mesmas, com ênfase as bibliotecas que atuam junto às escolas. Assim como também, é proeminente a construção de modelos de serviços que podem ser oferecidos com os social media, que possibilite a formação de comunidades em torno da literatura, biblioteca e a comunidade escolar. Assim, pretende-se, com a investigação, ratificar a biblioteca da escola como recurso educativo indispensável à formação de leitores críticos e criativos, demonstrando que, na Sociedade da Informação, a biblioteca deve valer-se de atividades educativas e lúdicas, tendo como instrumento os social media, para o incentivo à prática de leitura literária e da escrita.

Considera-se que o projeto Biblon, ao integrar simultaneamente o livro em formato de papel e digital, a literatura impressa e na web, pode trazer maior motivação para leitura e oferecer momento de interação de múltiplas linguagens. $\mathrm{O}$ trabalho com a literatura, dirigido para alunos de ciclos iniciais, tem como consequência o estímulo à prática da leitura literária e a formação de leitores, críticos e criativos. Destaque para a realidade de Portugal, onde os índices de leitores não atingem patamares ideais (PROGRAMME, 2009). Devido a esse contexto, a formação de comunidades de leitores, nessa fase escolar, incentivada pelo portal de biblioteca escolar, torna-se muito inovador e significativo.

Além do que, o contato das crianças com a tecnologia dos computadores, de forma lúdica e atrativa, colabora para o aprendizado das ferramentas da informática e conduz à inclusão digital com finalidade educativa (MORAN, 2006).

Em se tratando do incentivo do uso das tecnologias de informação e comunicação pela comunidade escolar portuguesa, o Ministério da Educação, com o Plano Tecnológico de Educação, desenvolve o Programa Magalhães que consiste na distribuição de computadores portáteis a alunos do $1^{\circ}$ ciclo da Educação Básica. Tendo início em setembro de 2008, o programa prever a distribuição de 500 mil computadores. O computador Magalhães inclui programas educativos destinados à aprendizagem da Língua Portuguesa, do Inglês, da Matemática e do Estudo do Meio, bem como um dicionário, um atlas e uma enciclopédia (PORTUGAL, 2008). 
A Associação para a Promoção e Desenvolvimento da Sociedade da Informação APDSI, através do Grupo de Alto Nível - GAN, organizou palestra titulada "As TIC e o ensino básico; o Computador Magalhães", com objetivo de expor avaliação qualitativa e quantitativa da iniciativa portuguesa. Com relação ao projeto em análise, o grupo detectou alguns aspectos relevantes como;

- A iniciativa abre leque de oportunidades económicas, sociais e políticas, podendo constituir uma importante componente da exportação de tecnologia, de conteúdos e de know-how, especialmente para países de língua oficial portuguesa,

- Os objetivos do projeto estão directamente associados a aspectos tecnológicos (computadores e conectividade à Internet),

- Não foi encontrada informação sobre objetivos associados à produção e exploração de conteúdos nem à formação,

- Falta de uma estratégia (clara e conhecida) para a componente de desenvolvimento de conteúdos e para os serviços de suporte à iniciativa (capacitação de docentes; suporte técnico; apoio às famílias;...),

- Não tem havido iniciativas suficientes na capacitação dos intervenientes nos processos de ensino/aprendizagem nem na mobilização dos docentes,

- Falta renovação do processo de ensino/aprendizagem. O investimento corre o risco de não ser potenciado caso não se demonstre o mesmo ímpeto no domínio dos novos modelos de aprendizagem e dos conteúdos,

- O modelo de utilização actual induz uma atitude consumidora e não produtora de conteúdos (ASSOCIAÇÃO, 2009).

A propósito, Alves (2010) constatou que a utilização do computador Magalhães “ainda é muito errática. Se algumas [escolas] o utilizam com frequência, outras já o puseram praticamente de lado [...] a sua utilização depende de cada professor".

Assim, pretende-se com o Portal Biblon, estimular o uso do computador Magalhães e expandir as formas de interação entre as crianças e destas com a literatura infantil. 
Com a experiência do Biblon considera-se a possibilidade de produção e de ampliação da presença de conteúdos na língua portuguesa no ambiente da web, já que o indicativo, segundo Guesser (2007, p.86), se apresenta ainda reduzido.

A esse respeito, a International Children's Digital Library - ICDL cita relatório da UNESCO (ORGANIZACIÓN, 2009) que declara; "A negação do acesso à informação na sua língua materna equivalente a uma negação de um direito humano [...] Em termos de pedagogia, como as crianças aprendem melhor? Na sua língua materna" (tradução nossa).

Com relação às bibliotecas escolares em Portugal, considera-se que a realidade das mesmas tem dois momentos distintos, o antes e o depois de 1996, ocasião da criação do Programa Rede de Bibliotecas Escolares.

A lei que determina a obrigatoriedade de bibliotecas nas escolas, em Portugal, data de 1948 e, em 1951, uma circular atribui competências aos professores responsáveis pelas bibliotecas. Porém, apesar da legislação, a situação é descrita por Calixto, em 1996, (p.19) como "quase um vazio legal, o que acarreta uma série de conseqüências que, na prática, inviabilizam o funcionamento das bibliotecas. [...] Há escolas em que a biblioteca simplesmente não funciona”.

Para sanar a precária realidade, os Ministérios da Educação e da Cultura constituíram um grupo de trabalho, com objetivo de elaborar um diagnóstico e propostas de ação para as bibliotecas escolares em Portugal. Como relatório do grupo tem-se o documento Lançar a Rede de Bibliotecas Escolares (VEIGA, 1996) que, além fazer um diagnóstico da situação que se encontravam as bibliotecas, contém os princípios gerais e as linhas de orientação para as bibliotecas escolares em Portugal, seguindo diretrizes de instituições internacionais, em especial da UNESCO e da IFLA.

Atendendo as recomendações do grupo de trabalho, foi criado o Gabinete de Rede de Bibliotecas Escolares, no despacho conjunto do Ministério da Educação e Ministério da Cultura, nº184/ME/MC/96. E ainda em 1996, foi instituído a Rede de Bibliotecas Escolares, para criação de bibliotecas escolares no sistema de ensino público, básico e secundário, subordinado à Direção-Geral de Inovação e Desenvolvimento Curricular - DGIDC, do Ministério da Educação.

Destaca-se que o relatório conceitua as bibliotecas escolares como InCID: R. Ci. Inf. e Doc., Ribeirão Preto, v. 2, n. 1, jan./jun. p. 68-85 , 2011. 
[...] espaços e equipamentos onde são recolhidos, tratados e disponibilizados todos os tipos de documentos (qualquer que seja a sua natureza e suporte) que constituem recursos pedagógicos quer para as actividades quotidianas de ensino, quer para actividades curriculares não lectivas, quer para ocupação de tempos livres e de lazer (VEIGA, 1996, p.33).

O Gabinete da Rede de Bibliotecas Escolares, instituído no Ministério da Educação é coordenador da Rede de Bibliotecas Escolares (RBE), que atua em conjunto com as Direções Regionais de Educação, Bibliotecas Públicas Municipais e instituições ligadas à área e tem como objetivo

instalar e desenvolver bibliotecas em escolas públicas, oferecendo recursos necessários à leitura, ao acesso, utilização e produção da informação em diferentes suportes [e, ainda,] desempenhar papel central no suporte às aprendizagens e no desenvolvimento de competências de informação e na formação de leitores (PORTUGAL, 1996).

As bibliotecas escolares, ligadas a RBE, têm como funções o desenvolvimento de competência informacional, formação de leitores e promoção do hábito de leitura e trabalham em uma estrutura transversal à escola e ao currículo.

Por ocasião dos 13 anos de implantação da RBE foi realizado, no dia 26 de junho de 2009, em Lisboa, o Fórum da Rede das Bibliotecas Escolares, com a participação de agentes envolvidos no sistema educacional, em particular professores bibliotecários. O objetivo do evento consistia em apresentar os resultados da avaliação do programa, realizado pelo Centro de Investigação e Estudos de Sociologia, do Instituto Universitário de Lisboa - ISCTE.

Dentre as conclusões do Instituto (2009, p. 138) destaca-se que o nível de execução do Programa Rede de Bibliotecas Escolares é elevado e que o objetivo do Programa tem vindo a ser atingido.

O ISCTE acentua que depois de mais de uma década de implantação a Rede de Bibliotecas Escolares deve suscitar novos objetivos e recomenda para futuras ações:

[...] incentivo às bibliotecas escolares a constituírem-se, plataformas de articulação, no processo educativo, entre a leitura, as aprendizagens curriculares, as TIC e a literacia da informação, e a constituírem-se, do mesmo passo, em plataformas de articulação, no quotidiano dos alunos, entre as leituras/escritas escolares e as leituras/escritas relacionais das gerações juvenis contemporâneas, as quais se estão a desenvolver de maneira intimamente integrada com as novas tecnologias de informação e comunicação (INSTITUTO, 2009, p. 147).

Dessa forma, considera-se que o projeto Biblon vem contribuir com a Rede de Bibliotecas Escolares, amenizando a lacuna, no diz respeito à leitura e a escrita em plataformas digitais, além de aproximar web, biblioteca escolar e crianças. 


\section{Conclusão}

Tomando por base os estudos e argumentos apresentados, percebe-se que a sociedade está em processo permanente de mudanças e nos últimos anos de uma maneira mais célere, em grande parte pelas tecnologias, que atingem mais intensamente as novas gerações.

Nesse sentido, as instituições que tem crianças e jovens como público alvo devem atentar para os novos paradigmas da geração que cresce no campo da interatividade da comunicação, da permuta e em um ambiente de múltiplas linguagens e convergências.

Com o advento das ferramentas sociais de tecnologia web, a leitura estreita sua relação com as novas gerações e com a escrita, onde a diversidade e heterogeneidade textual proporcionam um novo estilo de leitura e escrita.

A leitura tem sua abordagem ampliada e desvinculada da escola e do livro textual, já que está presente também em plataformas digitais, onde o leitor passa a ter um papel diferenciado, mais participativo e com oportunidade de expressão. A biblioteca escolar, com atuação decisiva na formação do leitor, se converte em ponto de informação e de encontro participativos, com temática principal em torno da literatura infantil, ao fazer uso das tecnologias sociais.

A plataforma Biblon se apresenta como uma iniciativa de fomentar a leitura e a escrita e a formação de redes em torno da literatura infantil, com participação central da biblioteca, contribuindo com sistema escolar da comunidade portuguesa.

\section{Referências}

ABRAMOVICH, F. Literatura infantil: gostosura e óbices. São Paulo: Scipione, 1994.

ALMEIDA, R. O leitor navegador. In: SILVA, E. (Org.). A leitura nos oceanos da internet. 2. ed. São Paulo: Cortez, 2008.

ALVES, T. Magalhães pouco usado em muitas escolas. Jornal de Noticias, 26 maio 2010. Disponível em:

$<$ http://jn.sapo.pt/PaginaInicial/Sociedade/Interior.aspx?content_id=1578316 > . Acesso em: 20 maio 2010.

ANDRADE, C. Confissões de Minas. Rio de Janeiro: América, 1944.

InCID: R. Ci. Inf. e Doc., Ribeirão Preto, v. 2, n. 1, jan./jun. p. 68-85 , 2011. 
ASSOCIAÇÃO PARA A PROMOÇÃO E DESENVOLVIMENTO DA SOCIEDADE DA INFORMAÇÃO. As TIC e o ensino básico: o computador Magalhães. Lisboa, dez. 2009. Disponível em: <http://www.apdsi.pt/>. Acesso em: 27 dez. 2010.

AUNIÓN, J. Los internautas leen mejor. El Pais, Madri, 3 jan. 2011. Disponível em: $<$ http://www.elpais.com/articulo/sociedad/internautas/leen/mejor/elpepisoc/20110103elpepiso c_1/Tes >. Acesso em: 04 jan. 2011.

BOURDIEU, P.; CHARTIER, R. A leitura: uma prática cultural. In: CHARTIER, R. Práticas de leitura. São Paulo: Estação Liberdade, 1996.

CALIXTO, J. A biblioteca escolar na sociedade da informação. Lisboa: Caminho da Educação, 1996.

CARR, N. O Google está nos tornando mais estúpidos, 2008. Disponível em: $<$ http://www.scribd.com/doc/15540363/Nicholas-Carr-O-Google-Esta-Nos-Tornando-MaisEstupidos >. Acesso em: 20 outubro 2010.

CELAYA, J. Innovación en el fomento de la lectura. Margen Cero: revista cultural de lectura rápida, n. 38, feb./mar. 2008. Disponível em:

$\leq \mathrm{http}$ ://www.margencero.com/articulos/articulos4/innovacion_lectura.htm $>$. Acesso em: 01 mar. 2009.

CHARTIER, R. A aventura do livro: do leitor ao navegador. São Paulo: UNESP/IMESP, 1999.

As práticas da escrita. São Paulo: Companhia das Letras, 1991.

Os desafios da escrita. São Paulo: UNESP, 2002.

ECO, U. Eletrônicos duram 10 anos; livros 5 séculos. Estadão.com.br, São Paulo, 13 mar. 2010. Disponível em:

$<$ http://www.estadao.com.br/noticias/arteelazer,eletronicos-duram-10-anos-livros--5-seculos-diz-umberto-eco,523700,0.htm>. Acesso em: 14 mar. 2010.

GUESSER, A. A diversidade lingüística da Internet como reação contra hegemônica das tendências de centralização do império. Ciência da Informação, Brasília, v. 36, n. 1, p. 7991, 2007.

INTERNATIONAL FEDERATION OF LIBRARY ASSOCIATIONS AND INSTITUTIONS. Manifesto IFLA/UNESCO para biblioteca escolar. Disponível em: $<$ http://www.ifla.org $>$. Acesso em: 20 nov. 2008.

INTERNATIONAL FEDERATION OF LIBRARY ASSOCIATIONS AND INSTITUTIONS. Libraries for children and young adults section, 2007. Reading for Pleasure. Disponível em:

$<$ http://www.chenyetsenfoundation.org/file/speech_content_Ivanka.doc $>$. Acesso em: 23 jul. 2010 . 
INSTITUTO UNIVERSITÁRIO DE LISBOA. Centro de Investigação e Estudos de Sociologia. Estudo de Avaliação do Programa Rede de Bibliotecas Escolares. Lisboa. Disponível em: <http://www.rbe.minedu.pt/np4/?newsId=591\&fileName=estudo_de_avalia_ao_programa_rbe.pdf $>$. Acesso em: 04 out. 2009.

MANDELLI, M. Jovens trocam livros por leitura digital. Estadão.com.br, São Paulo, 12 dez. 2010. Disponível em: <http://www.brasilquele.com.br/noticia_show.php?noticia=6461>. Acesso em: 13 dez. 2010.

MARTINS, M. O que é leitura. São Paulo: Brasiliense, 1983.

MEADE, $C$. The amplified author and the creative reader. In: CONFERENNCIA INTERNACIONAL DO PLANO NACIONAL DE LEITURA: LER NO SÉCULO XXI; LIVROS, LEITURAS E TECNOLOGIAS, 4., 2010, Lisboa (informação verbal).

MEIRELES, C. Problemas da literatura infantil. 3. ed. Rio de Janeiro: Nova Fronteira, 1984.

MILLÁN, J. (Org.). La lectura en España: informe 2008: leer para aprender. Madrid: Fundacion German Sanchez Ruiperez, 2008.

MORAN, J. (Org). Novas tecnologias e mediação pedagógica. São Paulo: Papirus, 2006.

O'REILLY, T. What is Web 2.0: design patterns and business models for the next generation of software, O'Reilly, 30 set. 2005. Disponível em: <http://oreilly.com/web2/archive/what-isweb-20.html>. Acesso em: 20 out. 2009.

PETIT, M. Os jovens e a leitura: uma nova perspectiva. São Paulo: 34, 2008.

PINTO, Z. Ler é mais importante do que estudar. ago. 2003. Disponível em: <http://www.ofaj.com.br/textos_conteudo.php?cod=21>. Acesso em: 20 nov. 2010.

PROGRAMME FOR INTERNATIONAL STUDENT ASSESSMENT. Results Learning to Learn: voulume 3. Disponível em:

$<$ http://www.oecd.org/document/2/0,3746,en_32252351_46584327_46609794_1_1_1_1,00.h

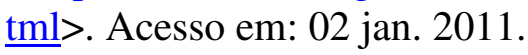

PORTUGAL. Ministério da Educação. Rede de bibliotecas escolares. Lisboa, 1996. Disponível em: $<$ http://www.rbe.min-du.pt/np4/?newsId=272\&fileName=brochuraRBE.pdf $>$. Acesso em: 15 dez. 2008.

PORTUGAL. Ministério da Educação. Plano Tecnológico de Educação. Programa Magalhães. Lisboa, 2008. Disponível em: <http://www.min-edu.pt/np3/2630.html >. Acesso em: 13 dez. 2008.

ROYCE, J. From literacy to information literacy: reading for understanding in the real world. In: ANNUAL CONFERENCE OF THE INTERNATIONAL ASSOCIATION OF SCHOOL 
LIBRARIANSHIP, 33. From Aesop to e-book: the story goes on... Dublin: IASL. 2004. p.254-267.

RÖSING, T.; SILVA, A. Práticas leitoras para uma cibercivilização. Universidade de Passo Fundo, 1999.

TAPSCOTT, D. A hora da geração digital. Rio de Janeiro: Agir Negócios, 2010.

ORGANIZACIÓN DE LAS NACIONES UNIDAS PARA LA EDUCACIÓN, LA CIENCIA Y LA CULTURA. World Summit on the Information Society. Disponível em: $<$ http://es.childrenslibrary.org/about/mission.shtml>. Acesso em: 16 maio 2009.

UNIVERSIA El 99\% de los jóvenes considera que las bibliotecas necesitan renovación. 2010. Disponível em: <http://www.universia.edu.pe/> . Acesso em: 27 dez. 2010.

VÁZQUEZ, J. Nuevos hábitos de lectura. Lectura en pantallas. Disponível em: $<$ http://www.dosdoce.com/articulo/opinion/3516/nuevos-habitos-de-lectura-lectura-enpantallas/>. Acesso em: 20 set. 2010.

VEIGA, I.(Org). Lançar a rede de bibliotecas escolares. Lisboa: Ministério da Educação, 1996. Disponível em: <http://www.rbe.min-edu.pt/>. Acesso em 24 nov. 2009.

ZILBERMAN, R. Fim do livro, fim dos leitores? São Paulo: SENAC, 2001.

WENGER, E. Communities of practice: learning, meaning and identity. Cambridge: University of Cambridge, 1998.

WENGER, E. et al. Cultivating communities of practice: a guide to managing knowledge. Boston: Harvard Business School Press, 2002. 